\title{
NIETZSCHE Y WAGNER: RENACIMIENTO DE LA TRAGEDIA GRIEGA
}

\author{
LAURA ROSA SILVESTRE \\ UNED \\ lrosa20@alumno.uned.es
}

\section{RESUMEN}

El objetivo del presente trabajo es ver hasta qué punto contribuyeron Nietzsche y Wagner a la recuperación de la tragedia griega y si esta era posible en el contexto del Romanticismo. La tesis que defenderemos será que, mientras que Nietzsche mantiene su postura de férreo defensor del carácter dual apolíneo-dionisíaco de la tragedia griega, Wagner, en sus últimas obras, como Parsifal, tomó ideas vinculadas a la moral cristiana, que hacían ver que sus pasos ya no seguían el camino conjunto con Nietzsche para restaurar una visión del mundo pesimista, como la de los helenos, por lo que, del proyecto inicial, poco queda más que el entusiasmo del comienzo.

PALABRAS CLAVE: Nietzsche; Wagner; tragedia griega; estética; revolución.

\section{NIETZSCHE AND WAGNER: REBIRTH OF THE GREEK DRAMA}

\section{ABSTRACT}

The aim of this paper is to point out how Nietzsche and Wagner's works contributed to the renewal of Ancient Greek drama. The thesis which is going to be defended in this paper is that Nietzsche and Wagner followed different paths: while Nietzsche stood as the representative of the duality apolinean-dionysiac from Ancient Greek drama, Wagner, in his Musikdramas, began to combine ideas of christian morality with the Ancient Greek model.

KEYWORDS: Nietzsche; Wagner; greek drama; aesthetics; revolution.

\section{INTRODUCCIÓN}

El presente trabajo tiene como objetivo ilustrar cómo Wagner y Nietzsche contribuyeron con sus ideas a la recuperación de la Tragedia Ática. Para ello, emplearemos El nacimiento de la tragedia de Nietzsche, donde podremos observar sus ideas, un tanto revolucionarias para el mundo de la filología clásica de aquel entonces. No debemos olvidar tampoco la relación amistosa de Wagner y Nietzsche. Además, emplearemos también textos correspondientes a las ideas de Wagner, para poder vislumbrar cuánto fue lo que Wagner innovó en el mundo dramático. No debemos olvidar tampoco la ruptura entre Wagner y Nietzsche y los escritos que Nietzsche dedicó al respecto: Nietzsche contra Wagner y El caso Wagner. Pero antes de entrar en cómo Nietzsche y Wagner entendían el arte, y en concreto el drama musical, debemos hacer una breve introducción a la tragedia griega ática y sus características. Además, hablaremos también, brevemente, de los intentos de reconstrucción de esta anteriores a Wagner y Nietzsche, esto es, las primeras óperas, para finalmente 
entrar en el verdadero cuerpo del trabajo: la teorización de Nietzsche acerca de cómo debía reconstruirse la tragedia griega, los ejemplos prácticos de Wagner, y cómo terminó la relación entre ambos, debido a la incapacidad de Wagner de realizar tal tarea, con la excepción de la tetralogía de El Anillo.

\section{LA TRAGEDIA ÁTICA: UNA INTRODUCCIÓN}

Primero, conviene que hagamos una breve incursión en el término tragedia griega y lo que simbolizaba en el contexto de la Grecia clásica. Aristóteles en su Poética describe qué es la tragedia:

La tragedia es la imitación de una acción seria y completa, de una extensión considerable, de un lenguaje sazonado, empleando cada tipo, por separado, en sus diferentes partes, y en la que tiene lugar la acción y no el relato, y que por medio de la compasión y del miedo logra la catarsis de tales padecimientos. [...] Una parte de la tragedia será el aderezo del espectáculo, y después la composición musical y la elocución, porque con estos medios llevan a cabo la imitación (Aristóteles, Poética, VI. Traducción de Alicia Villar [2004: 47-48])

Así pues, Aristóteles describe la tragedia como una imitación que debe constar de ciertos elementos de expresión artística, entre los que vislumbramos la poesía, la música y la danza, todos estos elementos integrados por igual en la representación. Esta concepción del drama como un conjunto de diversas expresiones artísticas, la veremos posteriormente en el concepto de Gesamtkunstwerk teorizado por Wagner.

Una de las características principales de la tragedia griega es su vinculación con la religión griega. La tragedia griega parece tener sus orígenes en los ditirambos, unos himnos cantados, acompañados de danza, en honor de Dionisos, y aparece también vinculada a la ciudad y a la democracia. ${ }^{1}$ La tragedia, además de las partes cantadas del coro, incluiría partes dialogadas entre los distintos personajes de la obra. La tragedia griega buscaba sus temas en el imaginario mítico conocido por todos los griegos, por lo que el espectador medio, cuando asistía a ver una representación, ya podía intentar anticipar, solamente conociendo el título de la tragedia, qué iba a suceder en dicha representación.

\footnotetext{
1 “La tragedia griega no es sólo una forma de arte: es una institución social que la ciudad, por la fundación de los concursos trágicos, sitúa al lado de sus órganos políticos y judiciales. Pero [aunque] la tragedia aparece así más arraigada que ningún otro género literario en la realidad social, ello no significa que sea su reflejo. No refleja esa realidad, la cuestiona" (Vernant y Vidal 1972: 26-27).

"La tragedia es parte activa de la polis no solo porque la polis está presente en todas sus fases (en la representación, en la organización, en el contenido mismo de las obras), sino porque es una actividad que contribuye a crear la unidad misma de la polis propiciando su autoconciencia, y a la vez cuestionando esta. [...] La tragedia desempeñaba algunas funciones sociales básicas: era un momento de fiesta, de entretenimiento, de diversión y de descanso, pero también era un ceremonial de culto" (Herreras 2010: 28-29).
} 
Aristóteles también dice sobre el argumento de la tragedia:

es necesario que un argumento bien articulado sea simple antes que doble, como dicen algunos, y no ha de pasar de la desdicha a la dicha, sino por el contrario, de la dicha a la desdicha; y no por maldad, sino por un fallo grave de un hombre como el que se ha dicho o de uno mejor, siempre preferible a uno peor. Y prueba de ello es lo que está ocurriendo: en efecto, al principio los poetas relataban al azar cualquier argumento; sin embargo ahora, las mejores tragedias se componen en torno a pocas familias, por ejemplo, en torno a Alcmeón, Edipo, Orestes, Meleagro, Tiestes, Télefo y a cuantos les aconteció sufrir o hacer cosas terribles (Aristóteles, Poética, VI. Traducción de Alicia Villar [2004: 64-65]).

Debemos destacar, sobre todo, el carácter político y social de la tragedia, que aparece dirigida a toda la sociedad -aunque debemos entender que con esto se refiere a los ciudadanos-, vinculada a la polis y a los valores democráticos y también vinculada al culto religioso, por su carácter ritual y cíclico -ya que se representaban las tragedias en las Grandes Dionisias. Para cada festival el autor componía una nueva tetralogía, por lo que las tragedias se representaban solamente una vez.

\section{INTENTOS DE RECONSTRUCCIÓN DE LA TRAGEDIA ÁTICA: LA ÓPERA}

Durante el Renacimiento, época histórica caracterizada por el retorno a los valores clásicos de Grecia y Roma, encontramos diversos intentos de reconstruir la tragedia griega. El primer intento fue llevado a cabo por Andrea Gabrielli, quien presentó para la inauguración del Teatro de Vicenza en el año 1585 una versión de la tragedia Edipo Rey, de Sófocles. Este intento no resultó fructífero, debido a que la obra no tenía un contenido original -era una mera imitación de la obra de Sófocles-, no tenía la finalidad política y social característica de la tragedia griega -puesto que la representación era elitista, ya que solo albergó a los poderosos-, ni presentaba la armónica estructura de un conjunto de poesía, música y danza.

Otro intento fue llevado a cabo por la llamada Camerata Fiorentina, representada principalmente por Vicenzo Galilei. De algunos estudiosos que habían pertenecido a dicha asociación surgen las primeras óperas: Dafne (1597) de Jacopo Peri y La favola d'Orfeo (1607) de Claudio Monteverdi. De estas primeras óperas debemos destacar que su temática es común, la fábula pastoril basada en la mitología. Aunque estos estudiosos tuvieron buena intención en el intento de resucitar la tragedia griega, no lo lograron, debido a que las obras no estaban estructuradas en trilogías, no tenían un fin político ni social como en Grecia, ni aparecía ningún tipo de competición agónica, parte indispensable en la estructura de la tragedia ática. Además, deberíamos añadir que carecían de un sentido ritual, pues no estaban vinculadas a ningún tipo de celebración religiosa.

Pero, ¿estuvieron todos los teóricos de la música equivocados en cuanto al planteamiento de la reconstrucción de la tragedia griega? Con la reforma de 
Gluck, ${ }^{2}$ la ópera se transforma y comienza a asemejarse más al concepto de tragedia griega. Este supedita la música a la poesía -rasgo importante que luego encontraremos en la Gesamtkunstwerk de Wagner- y eleva a los héroes de sus óperas, tal y como los trágicos griegos acostumbraban a hacer. No debemos olvidar tampoco que su ópera se articuló como una ópera sencilla, al alcance de todos, lo que permite que haya un fin social, como en la tragedia ática. Pero es con Mozart donde la ópera adquiere un parecido más razonable con la tragedia griega: Mozart comprendió el concepto de mousiké griego y así lo reflejan sus óperas, a pesar de que Grecia no fue tanto su fuente de inspiración mítica como Roma.

Debemos considerar, pues, que la ópera surgió como una especie de reconstrucción del drama antiguo de la Grecia clásica, aunque no cumplió con su cometido. $\mathrm{Y}$ es con Wagner cuando la tragedia griega se verá de nuevo en escena. Esto es así porque, como veremos que Nietzsche defiende, Wagner incorpora a sus dramas musicales un aspecto esencial de la tragedia griega: su utilización para la transmisión al público de una actitud determinada -que en Grecia había sido lo que Nietzsche denominará pesimismo o helenismo.

\section{EL NACIMIENTO DE LA TRAGEDIA Y SU POLÉMICA}

El nacimiento de la tragedia, opera prima de Nietzsche, resultó ser un escrito filosófico que nació de sus conocimientos filológicos -philosophia facta est quae philologia fuit. En dicha obra observamos una serie de conceptos que son clave para entender la teoría estética de Nietzsche. Según el filósofo alemán, existen en el mundo dos instintos artísticos fundamentales, que él denomina apolíneo y dionisíaco. Dichos instintos primordiales, que serán una parte fundamental de la estética nietzscheana, están representados por dos dioses contrapuestos: Apolo y Dionisos.

Podemos describir lo apolíneo como aquello propio del arte canónico, esto es, la arquitectura o la escultura, de la poesía; podemos decir, por tanto, que lo apolíneo está presente en las manifestaciones artísticas reguladas por un orden. Por su parte, lo dionisíaco sería aquello propio de la música, del éxtasis orgiástico y del caos -la música sería una manifestación artística que no estaría regida por un orden; la música es instintiva. De hecho, Nietzsche señala que la música es la experiencia dionisíaca pura: al no contener palabras, no introduce

\footnotetext{
${ }^{2}$ La ópera presentará una transformación durante el siglo XVIII, con las reformas de Gluck y con las óperas de Mozart. Gluck transforma la ópera en un arte más parecido a lo que después concebirá Wagner. Ya encontramos en sus obras operísticas una mayor sencillez en cuanto a los cantos, pues ya no habrá florituras superfluas, y vemos cómo subordina en mayor grado la música a la poesía, de modo que en la ópera se pueda expresar los sentimientos y las pasiones del drama humano. En cuanto al hecho de que subordina la música al texto, debemos especificar que anteriormente la música tenía mucha más importancia que el texto, para la transmisión de los sentimientos, pero Gluck intenta otorgar el mismo valor a ambos, como más tarde intentará llevar a cabo Wagner.
} 
ningún significado, sino pura sensación, es decir, no se interpreta de ningún modo -racional o moralmente- la realidad, ${ }^{3}$ sino que simplemente expresa sentimiento, sensación -esto, como veremos, se presentará opuesto a la Obra de Arte Total wagneriana, puesto que Wagner supeditará la música a la poesía, otorgándole una interpretación de la realidad y haciendo de la música un arte más apolíneo. Lo apolíneo es la apariencia de las apariencias -el arte apolíneo siempre es susceptible de interpretación racional- mientras que lo dionisíaco es la apariencia del ser mismo -la música, experiencia dionisíaca por antonomasia, no incita a una interpretación racional, sino que es la forma de percibir la realidad sin emplear la razón, en tanto que no emplea el lenguaje, el logos.

Los siguientes conceptos que debemos aclarar son el de pesimismo y el de optimismo y cómo el pesimismo formó parte de la cultura helena. ¿Qué entiende Nietzsche por pesimismo en la etapa en que escribe El nacimiento de la tragedia?4

Los conceptos de pesimismo y optimismo son dos nociones contrapuestas que aparecen vinculadas a una determinada actitud ante la vida y la realidad. Para Nietzsche, la visión pesimista de la realidad sería aquella que acepta la realidad como algo cruel y doloroso. Frente a esto, hallaríamos una actitud optimista, que buscaría una "realidad" más allá del mundo cruel, para poder vivir felizmente y sin sufrimiento. El pesimismo invita a vivir la vida tal y como se presenta, como algo cruel y doloroso que es, mientras que el optimismo niega la vida, supeditándola a un mundo o una vida ulterior, que se presupone mejor que esta. Nietzsche muestra el pesimismo encarnado por la sociedad helena, cuyo mayor representante es la tragedia griega, mientras que el optimismo vendría a ser la actitud para con la vida de Sócrates o los cristianos.

¿Por qué es pesimista la Grecia clásica? Como hemos puntualizado, una actitud pesimista para con la vida estaría caracterizada por la aceptación de la vida tal y como es -aunque la vida sea cruel y dolorosa- y por el llamamiento a vivirla. La tragedia griega encarnaría a la perfección esta concepción pesimista

\footnotetext{
${ }^{3}$ La filosofía de Nietzsche postula que la realidad se percibe mediante los sentidos, de una forma empírica, mientras que la razón es un instrumento que ayuda a comprender dicha realidad pero que no la muestra (la razón interpreta la realidad, la falsea). En la filosofía nietzscheana, hallamos que la realidad no debe confundirse con aquello que interpretamos de modo racional, sino que aquello que percibimos con nuestros sentidos es la auténtica realidad. Nietzsche también argumenta que no debemos confundir la realidad con su interpretación moral o racional (no debemos olvidar que los socráticos o los cristianos interpretaron la realidad como un mundo falso y consideraron un mundo ulterior como el mundo verdadero, véase el Mundo de las Ideas de Platón o el Cielo cristiano).

${ }^{4}$ El concepto pesimismo no tiene el mismo significado en toda la filosofía de Nietzsche. Mientras que en su primera obra, El nacimiento de la tragedia, representa la aceptación del destino y de la vida cruel, mucho tiempo después, en su obra Humano, demasiado humano, encontramos dos tipos de pesimismo: el pesimismo de la fortaleza -que se corresponde con el ya explicado en El nacimiento de la tragedia- y el pesimismo romántico -que vinculará a Wagner y al cristianismo. Para profundizar en este aspecto sería interesante la lectura del artículo de Meléndez (2004), "La profundización del pesimismo como clave de continuidad en el pensamiento de Nietzsche".
} 
de la vida, ya que en ella, los héroes, no importa qué hagan, están subordinados a los designios divinos y sus destinos ya están predeterminados por los dioses. Así, el héroe debe aceptar que aquello que el dios ha vaticinado acabará convirtiéndose en realidad, puesto que la voluntad divina es inescrutable. Así, esta actitud que la tragedia griega muestra puede ser considerada como un ejemplo de pesimismo en tanto que llama a la aceptación de cuanto sobrevenga, a aceptar la realidad sea como sea, de forma similar a como propugnaba el estoicismo. El pesimismo helénico es, en palabras de Herreras,

una inclinación intelectual a la dureza, al horror, al mal, a la incertidumbre de la existencia, producida por la exuberancia de la salud del exceso de vida. Y es desde dicha elucubración desde donde surge su principal tesis, la que habla del socratismo de la moral, de esa dialéctica, de esa suficiencia y seguridad del hombre teórico que provocaron la muerte de la tragedia (Herreras 2010: 289).

Nietzsche postula que la vida no es un medio para conseguir un fin como el cielo del cristianismo, sino que la vida es el fin mismo. El cristianismo, para Nietzsche, niega el mundo: coloca el objetivo de la vida en un mundo, el Cielo, más allá de la propia vida -siguiendo, en parte, el dualismo ontológico platónico. Para Nietzsche, esta es una actitud propia de débiles, esto es, de aquellos que no son capaces de afrontar la realidad, aquellos para los que esta resulta demasiado dura y necesitan crear una vida más allá de esta.

La actitud pesimista, tal como la que hallamos en Grecia, es, por tanto, contrapuesta al cristianismo. La filosofía de Nietzsche, contrapuesta al optimismo cristiano, sería, pues, el vitalismo, que clama por una aceptación de la realidad con todas sus penurias, sin tener que inventar elementos externos a dicha realidad, como el Cielo cristiano.

Por tanto, Nietzsche se convierte en un férreo detractor de la moral cristiana. Afirma que la moral cristiana está fundada por débiles y se dirige a débiles, mientras que el pesimismo griego encarna la aceptación de la cruda realidad, y constituye, por ello, un llamamiento a la vida.

La tragedia griega es una conjunción de lo apolíneo y lo dionisíaco. Como hemos mencionado anteriormente, la poesía es algo propio de lo apolíneo y la música es aquello que mejor representa el espíritu dionisíaco. Podríamos decir que la imagen de Dionisos con una máscara de Apolo representaría a la tragedia griega muy acertadamente. En esta dicotomía apolíneo/dionisíaco encontramos evidente que la palabra (apolínea) y la música (dionisíaca) se encuentran enzarzadas en una lucha por dominar a la otra, pero nunca deben sobreponerse la una a la otra, ya que "ambas dimensiones juntas [esto es, lo apolíneo y lo dionisíaco] producen en la conciencia la representación clara de los poderes del destino" (Safranski 2000: 67).

Según Nietzsche la tragedia griega perderá su primitiva fuerza tal como el logos se vaya apoderando de la escena: cuando el logos domine al pathos. Nietzsche también señala que, lo que hace de la tragedia aquello que es, es 
precisamente el equilibrio de poder entre el instinto apolíneo y el instinto dionisíaco. Por eso, argumenta en su obra que el momento en que la tragedia se sume en la decadencia es precisamente cuando se separan los dos instintos y uno de ellos se superpone al otro: la tragedia, su pathos, se racionaliza. Esta racionalización de la tragedia dice Nietzsche que está representada por Sócrates y Eurípides.

Sócrates rompe el poder de la música y pone en su lugar la dialéctica. Sócrates constituye una fatalidad, pues con él comienza un racionalismo que ya nada quiere saber de la profundidad del ser. Sócrates es el comienzo de un saber sin sabiduría. Concretamente, el "pathos" del destino (en la tragedia) fue desplazado por el cálculo, las intrigas y las previsiones. Nietzsche considera a Sócrates como síntoma de un profundo cambio cultural, cuyas consecuencias perduran hasta hoy. La voluntad de saber se sobrepone a los poderes vitales del mito, de la religión y del arte. La conferencia de Nietzsche termina con susurrantes observaciones sobre el posible renacimiento de la tragedia griega (Safranski 2000: 65-66).

La razón por la que Sócrates, y más tarde Eurípides, dan muerte a la tragedia es el hecho de que Sócrates, como filósofo, empezó a preguntar por la verdad, es decir, tomaba el mundo como ya dado en lugar de crearlo. Mientras los griegos se preguntaban qué puedo hacer o qué me hace fuerte, Sócrates se pregunta qué es aquello verdadero; los griegos estaban dando forma al mundo, pero Sócrates cambia la creación por el reconocimiento del mundo. Es así como Occidente perdió su creatividad: el mundo estaba ya hecho y no se le daba forma. Así pues, la tragedia, cuya función era transmitir unas ideas que cambiasen el mundo, pierde su cometido. El arte se fosiliza, ya no es ni apolíneo ni dionisíaco, sino simplemente socrático.

Pero, ¿qué sucede para que la tragedia griega no pueda volver a instaurarse en el mundo occidental? Nietzsche argumenta que, tras la muerte de la tragedia, sucedieron unos dos mil años de filosofía: la razón triunfó sobre el pathos. Para Nietzsche, lo dionisíaco constituía el fondo de la tragedia, mientras que lo apolíneo constituía la forma (cf. Barrios 2002: 92).

Sócrates es para Nietzsche la figura que encarnaría la muerte de la tragedia. Esto se debe a la propugnación socrática de que el ideal estético de belleza debe ser inteligible, esto es, comprensible racionalmente. Es en la tragedia euripidea (marcada por el pensamiento socrático) donde se pierde poco a poco el rasgo dionisíaco de la tragedia y esta acaba racionalizándose y moralizándose. Nietzsche afirma, pues, que el espíritu de la música es quien da vida a la tragedia -por eso, al eliminar Eurípides y Sócrates dicho elemento dionisíaco acabarán dando muerte a la tragedia.

Pero, ¿qué hará que no sea posible reinstaurar la tragedia griega en el Romanticismo? Así como hemos nombrado a los socráticos como portadores del optimismo, así serán también los cristianos. El cristianismo, como hemos puntualizado anteriormente, es optimista, en tanto que niega la vida -por medio de la negación de los instintos vitales- y muestra como verdadera la vida 
que se ha de vivir tras la muerte, creando un mundo ulterior "verdadero". Mientras que el influjo del cristianismo siga vigente en la cultura occidental, resultará imposible restaurar la tragedia griega, representante del pesimismo helénico. ${ }^{5}$

A modo de conclusión, debemos considerar que Nietzsche aparece en el Romanticismo como un reconciliador de la tradición clásica; pretende que su época regrese al primer pesimismo para albergar un florecimiento cultural tal como el de la tragedia griega con Esquilo y Sófocles. Nietzsche, tras conocer a Richard Wagner, ve en él y en su música el remedio para reinstaurar el arte clásico en el Romanticismo, aunque, más tarde, veremos que cree posible esta reinstauración durante muy poco tiempo.

\section{WAGNER COMO REVOLUCIONARIO DEL ARTE}

Richard Wagner fue, además de compositor, teórico del arte y la estética. En sus tratados artísticos, Wagner intentaba lanzar el mensaje de que, para poder llevar a cabo una revolución social y política, primero se debía llevar a cabo una revolución artística. Wagner consideraba que esta revolución artística solo podía darse si se reconciliaban todas las artes y logrando lo que él denominó la Obra de Arte Total (Gesamtkunstwerk), esto es, una obra de arte donde se aunaban la poesía, la música y la danza. ¿A qué recuerda esta Obra de Arte Total? Wagner se inspira en la tragedia griega al postular esta teoría -aunque no solamente en ella, sino también en los dramas shakespearianos y la música de Beethoven. ¿Por qué pensaba Wagner en una revolución? Consideraba que el mundo estaba corrompido y que, para solucionarlo, se necesitaba una revolución artística -el orden social corrupto corrompió al arte. Lo que Wagner intenta transmitir en sus obras es una cierta actitud frente a la vida a fin de renovar la ideología de sus contemporáneos y, de ese modo, renovar la sociedad romántica, hacer la revolución. Wagner intentará regresar a la tragedia griega, que se concebía como una experiencia social, para identificar con la obra de arte al Volk alemán y dotarle de una identidad.

Wagner propugna como modelo ideal de reinstauración de la tragedia griega, lo que hemos mencionado anteriormente como Obra de Arte Total. En dicha obra, encontramos que la música, la poesía y la danza aparecen congregados en la misma expresión artística.

\footnotetext{
${ }^{5}$ El optimismo queda, pues, representado por el socratismo, el cristianismo y la ciencia. El cristianismo se muestra opuesto particularmente a la concepción helénica del destino imperturbable y de la crueldad de la vida. La ciencia de la Ilustración se antepone a la decadente y pesimista época del Romanticismo. Quizás debido a la decadencia del Romanticismo y a su pesimismo, esta época sea la idónea para la restauración de la tragedia griega, debido a que, al igual que el período helénico, está caracterizada por el pesimismo y porque se presenta como una época más liberada de la moral cristiana.
} 
Mientras que Nietzsche estaba "en perfecto acuerdo con la teoría schopenhaueriana, [que consideraba que] la música, y no la acción, habría de ser la parte fundamental en la obra dramática, Wagner [consideró] el texto como significado de expresión indispensable a la música, ya que aquel ocuparía una posición subordinada que nunca debía abandonar" (Pérez Maseda 2004: 265).

En este sentido, Nietzsche y Schopenhauer estarían alejados de Wagner, puesto que no consideraban absolutamente necesario emplear la poesía para dar mayor expresión a la música -Nietzsche considera que la música es la experiencia dionisíaca pura y es puro sentimiento. Para Wagner, "si bien música y poesía tenían independientes funciones, cada una de ellas podría hallar su más alta realización abandonando su identidad en una nueva unidad que daría, a su vez, una nueva forma de arte": el drama musical wagneriano, deudor de la tragedia griega, de la obra shakespeariana y de la música de Beethoven (Pérez Maseda 2004: 265).

La obra wagneriana que más se acerca a sus teorías estéticas es la tetralogía de El Anillo, y concretamente su prólogo, “El oro del Rin”. A pesar de que Wagner no concibe su drama musical sin la presencia de la poesía, la orquesta wagneriana tiene un papel importante en el desarrollo de la obra. Mientras que en la ópera se daba una especial atención a los cantantes, Wagner dotará a la orquesta de un papel principal, puesto que servirá como elemento continuo que enlaza todo el drama musical; Nietzsche la llamó "la melodía sin fin", de un modo despectivo, puesto que no considera que esta melodía esté concebida para la danza, tal y como debemos presuponer que está concebida la música. Así, el papel de la orquesta es primordial para entender el drama musical de Wagner, ya que es la orquesta la que se encarga de mostrar los pensamientos y sentimientos de los personajes. Observamos que, aunque el texto es importante en la obra de Wagner, no tienen tanta importancia los cantos, que pasan a ser más líricos que en la ópera tradicional.

¿Por qué Wagner no pudo reinstaurar con sus dramas musicales la antigua tragedia griega? Wagner hace uso de la mitología germánica y las sagas islandesas para componer su famosa Tetralogía: con esto, el compositor pretende dotar al pueblo alemán de una identidad colectiva, crear el concepto de Volk alemán. Wagner intenta incluir dicha noción en su obra porque de este modo hace partícipe al pueblo de su propia obra y así intenta asentar las bases de lo que sería un futuro más próspero -de esta idealización del pueblo alemán más tarde surgirá el mito nazi. A pesar de esto, la obra de la tetralogía no celebra a los antiguos dioses, sino que intenta desplazarlos, para poder alcanzar un futuro quizás mejor -esto lo vinculará Nietzsche con lo que él denominará pesimismo romántico, como veremos más adelante. Es bastante remarcable la forma del drama musical de El Anillo. Con su forma tetralógica, recuerda a las composiciones que los trágicos griegos preparaban para los festivales de Dionisos. Pero debemos destacar una diferencia en el proceso creativo: la obra 
trágica helena tiene sus bases en una religión que celebra la vida -la vida como algo cruel, doloroso y cuya naturaleza debemos aceptar-, mientras que la obra de Wagner, con un trasfondo cultural europeo, que tiene sus bases en el cristianismo, se basa en una religión que niega la vida: Wagner en cada una de sus óperas crea mundos imaginarios, donde se desarrollan cada una de las tramas.

A pesar de esto, el intento de reconstrucción de la tragedia griega por parte de Wagner es el que más se aproxima a aquello que consideramos que fue la tragedia griega antigua (una conjunción de las artes -música, poesía y danzaque tenían la misma importancia en la obra).

\section{NIETZSCHE CONTRA WAGNER Y EL CASO WAGNER}

¿Cuándo se produjo la ruptura entre Nietzsche y Wagner? La mayor parte de los estudiosos señalarán que esta ruptura se produjo cuando Wagner concibió Parsifal, un drama musical que se acerca a la moralidad cristiana. Pero el autor Pérez Maseda nos sitúa dicha ruptura mucho tiempo atrás, en El nacimiento de la tragedia, tal y como observamos en el pasaje citado a continuación:

cuando Nietzsche redactaba El nacimiento de la tragedia ya había dejado de ser wagneriano. [...] Existe, por supuesto, una salida abrupta de Nietzsche en su relación con Wagner: una "acción", que es la primera que se manifiesta como brusca y realmente sincera, que no es otra que su huida de los primeros Festivales de Bayreuth en agosto de 1876. [...] Basándose en el "wagnerianismo" sin más de Nietzsche, se puede afirmar tanto que este no era ya wagneriano en junio de 1872, como que "wagneriano" lo fue toda su vida (Pérez Maseda 2004: 264).

Nietzsche observa cómo los dramas musicales de Wagner no reflejan completamente las teorías estéticas que ambos comparten y se aleja del ideal que ambos consideran el objetivo a alcanzar. Wagner, para Nietzsche, deja de lado el pesimismo helénico y pasa a ser un representante del pesimismo romántico, que tiene relación con el cristianismo. Como hemos dicho anteriormente, Nietzsche en su obra Humano, demasiado humano introduce dos tipos de pesimismo: el pesimismo de la fortaleza -el propio de los griegos- y el pesimismo romántico. Este segundo pesimismo se muestra como el más peligroso de todos. "Nietzsche nos revela con el ejemplo de Wagner cuál es el tipo de romanticismo que en opinión suya encarna la más peligrosa de las formas: este no es otro que el tipo de romanticismo que termina postrándose ante la cruz" (Meléndez 2004: 9). ¿Qué entiende Nietzsche por pesimismo romántico? Este tipo de pesimismo vendría a ser una actitud de negación de la vida y del mundo -similar a lo que Nietzsche denomina, en El nacimiento de la tragedia, optimismo cristiano. Nietzsche nos explica de este modo su concepto de pesimismo romántico: a partir de las premisas del dolor y el sufrimiento individual, se hace un juicio universal sobre el mundo y la vida, con lo que se juzga a estos como negativos, de forma similar al cristianismo. Esta actitud, 
propia del romanticismo, lleva a refugiarse en otra realidad. Mientras que el arte griego se presentaba como un arte potente y surgido de los instintos creadores de la naturaleza, este arte romántico surge del sufrimiento personal pero no es instintivo, debido a que niega tanto la vida como la realidad. Wagner, situado en este contexto decadente, propugnará la idea de una unidad del pueblo alemán, de modo que este ideal representará un mundo mejor que el actual, es decir, Wagner, al igual que el cristianismo, se refugia del mundo y propone un camino hacia un ideal, hacia un mundo mejor -en este caso será una supuesta mejor sociedad alemana; es, por tanto, un ideal de redención frente al mundo, como el Cielo cristiano. Nietzsche rompe con Wagner cuando este último abraza en sus dramas musicales la moral cristiana. Nietzsche dice de Wagner en sus escritos tardíos:

el último Wagner, pienso en su Parsifal, ha transigido no sólo con el romanticismo sino precisamente con el gusto romano-católico: hasta que finalmente se despidió con una genuflexión ante la cruz y con una sed sin adornos "de sangre del redentor" (Junio-Julio 1885) (Nietzsche 1999: 96, fragmento 189).

Wagner abandona en esta última obra la mitología germánica en favor de las leyendas medievales del Santo Grial: Wagner ha hincado la rodilla ante el cristianismo. Para Nietzsche, tal como observamos en su filosofía, Wagner ha abandonado la fuerza del pesimismo griego ante la vida en favor de la debilidad propugnada por la moral cristiana. Nietzsche romperá relaciones con Wagner, ya que él no abandonará la actitud vitalista. Para Nietzsche, la ópera wagneriana "vendría a ejemplificar algunas de las peores características de la decadente cultura moderna" (Byrne 2002: 19).

Nietzsche en El caso Wagner arremete contra el compositor con acusaciones como que "su ópera es la ópera de la redención" (Nietzsche 2003: 194). Este concepto de redención estaría a medio camino entre "la resignación schopenhaueriana y lo que Nietzsche considera una especie de optimismo cristiano" (Pérez Maseda 2004: 266). Para Nietzsche la obra dramática de Wagner sería demasiado

"moderna", ya que está cargada de una fusión de arte y moralidad y poco a poco este coloca a la obra de Wagner cada vez más al lado de la "ópera", cada vez más ligada a lo "moral", a lo "racional" incluso, y alejada del ideal griego, de la concepción dionisíaca de la música en la tragedia griega (Pérez Maseda 2004: 266).

Y no es de extrañar que Nietzsche, en su obra El caso Wagner, diga que Wagner no es un compositor instintivo (cfr. Nietzsche 2003: 213).

Por tanto, podemos decir que Nietzsche considera a Wagner un artista decadente desde la primera de sus obras hasta la última, aunque en ciertos momentos de su vida se muestre maravillado con el proyecto que Wagner emprende. Considera que en todos los dramas musicales wagnerianos podemos hallar una interpretación redentora -incluso en El Anillo, que se muestra como una obra que trata de forjar un futuro mejor frente al pasado. 


\section{CONCLUSIONES}

En este trabajo hemos comenzado viendo el trasfondo de la tragedia griega -cuáles eran sus características fundamentales- $y$, a continuación, a modo de contextualización, hemos hecho un repaso de los intentos operísticos de revivir la tragedia griega antigua. El objetivo del trabajo era poder mostrar por qué ni Nietzsche ni Wagner pudieron lograr la restauración de dicho espectáculo dramático. Nietzsche postula, en su obra El nacimiento de la tragedia, que aquello que otorga fuerza a la tragedia griega es su actitud pesimista para con la vida -como pesimismo aquí entendemos "pesimismo de la fortaleza". Wagner se fija en Grecia como ideal, sobre todo, por la forma del drama griego, que le parece el mejor vehículo disponible para revolucionar el arte y el mundo. El problema que se presenta como imposibilidad de la renovación de la tragedia griega es que la sociedad romántica tiene sus bases en la cultura europea cristianizada, y dicha doctrina cristiana se muestra contraria a los ideales que persigue el drama antiguo -al contrario que la tragedia griega, niega la vida. Wagner mismo, a pesar de haber comprendido la función de la tragedia griega, acaba cayendo en lo que Nietzsche llama pesimismo romántico y quizás también en el optimismo cristiano, y acaba introduciendo en sus obras la redención en lugar de la aceptación de la realidad tal y como es. El conflicto entre Nietzsche y Wagner aparece, más bien, debido a los objetivos perseguidos por cada uno de ellos: mientras que Nietzsche concebía el arte griego como una forma de vitalismo, Wagner ve en este arte griego la solución para renovar la sociedad de la que él es contemporáneo, haciendo uso de unos nuevos ideales y nuevos mundos creados por él. Deberíamos puntualizar que Nietzsche busca Grecia como ideal para afrontar la vida y Wagner se centra en la tragedia griega como modelo perfecto para la transmisión de unos nuevos ideales, aunque estos no sean griegos. Nietzsche busca lo dionisíaco -el fondo-, y Wagner, lo apolíneo -la forma.

BIBLIOGRAFÍA

ARISTÓteles (2004), Poética, Madrid, Clásicos de Grecia y Roma, Alianza Editorial. (Traducción, introducción y notas de Alicia Villar Lecumberri).

BARrios CASARES, M. (2002), Voluntad de lo trágico: El concepto nietzscheano de voluntad a partir del Nacimiento de la Tragedia, Madrid, Editorial Biblioteca Nueva.

BERRY, M. (2004), "Richard Wagner and the Politics of Music-Drama", en The Historical Journal, Volumen 47, Número 3, septiembre 2004, páginas 663-683.

BYRNE, W. (2002), "Nietzsche's rejection of Wagner: Aesthetics, ethics and politics", en Commonwealth: A Journal of Political Science, volumen 11, año 2002.

GÓMEZ, T. (2000), El lector de... Friedrich Nietzsche, Barcelona, Editorial Oceano.

HERRERAS, E. (2010), La tragedia y los mitos democráticos, Madrid, Editorial Biblioteca Nueva. 
MELENDEZ ACUNA, G. (2004), “L'approfondissement du opessimisme comme clé de la formation de la pensée de Nietzsche", en Nietzsche. Philosophie de l'esprit libre, Francia, Éditions Rue D'Ulm , v. , p.61-78 (Versión española del capítulo).

Nietzsche, F. (1999), Estética y teoría de las artes, Madrid, Editorial Tecnos. (Prólogo, selección y traducción de Agustín Izquierdo).

NiETZSCHE, F. (2003), Escritos sobre Wagner, Madrid, Biblioteca Nueva. (Traducción de J.B. Llinares).

NiETZSCHE, F. (2012), El nacimiento de la tragedia: o Grecia y el pesimismo, Madrid Alianza Editorial. (Introducción, traducción y notas de Andrés Sánchez Pascual).

PÉReZ MasedA, E. (2004), El Wagner de las ideologías: Nietzsche-Wagner, Madrid, Biblioteca Nueva.

Portales, G. (2012), “Nietzsche-Wagner. Preminencia de la poesía en la Obra de Arte Total", en Estudios filológicos, número 49, páginas 117-125.

ROYO HERNÁNDEZ, S. (2007), “Friedrich Nietzsche: la renovación de la paideia y la polémica sobre el Nacimiento de la Tragedia", en A Parte Rei, número 54, noviembre 2007.

VERNANT, J.-P. y VIDAL-NAQUET, P. (1972), Mito y tragedia en la Grecia antigua, edición española de 1987, Madrid, editorial Taurus. (Traducción de Mauro Armiño). 